Vol. 5, No. 2, 2018

https://doi.org/10.23939/eem2018.02.051

UDC 657.631

V.Shkvir

$\mathrm{PhD}$ in Economics, Associate Professor

I. Borshchuk

$\mathrm{PhD}$ in Economics, Associate Professor

Lviv Polytechnic National University

\title{
METHODOLOGY OF CONSTRUCTION ACCOUNTING NOMENCLATURE CODES OF NON-AUTOMATIC INFORMATIONAL BASE OF COMPUTER ACCOUNTING SYSTEM
}

\begin{abstract}
The basic approaches for creation a computer accounting informational system (KIS-BO) have been determined and the theoretical aspects of designing non-automatic information base (IB) have been found out. The main emphasis is on such a component of ectopic IB, as the codes of accounting nomenclature, because the further effective exploitation of KIS-BO depends on their rational construction. It is shown that classification and encoding is an undivided creation and operation element of the computer informational base. The aim of classification and encoding is to order and coordinate various objects, concepts, properties or other elements of information. The employment of codes can significantly reduce the amount of information and the complexity of its processing at all stages of the technological process of automated data processing.

The method of designing codes of accounting nomenclature is proposed and an example of this implementation is given.
\end{abstract}

Key words: computer information accounting system, information support, non-authomatic information base, machine information base, classification and encoding of information.

\section{The formulation of the problem}

Nowadays, there are a lot of options for creating computer accounting information systems that can be purchased as a product in the form of a set of software, a so-called "by pattern" solution (including foreign programs). Another approach is to buy and integrate components. It is also possible that the development of the system is transferred to a third side in order to reduce costs. Although the options are considered especially for sufficiently financially strong enterprises, on which it is possible to build an information system on its own.
Regardless of the variants of creation of KIS-BO, for which specialists develop a machine-based information base in a qualified manner, the issue of designing a machine-based information base of such a system remains incomplete. Mostly, KIS-BO does not count the specifics of the company's operating, which will exploit this system. The most important part of the machine tool IB are codes of the accounting nomenclature, because the encoding allows to establish the uniformity of the representation of all the signs, bring the information into a convenient for computer input and processing form, etc.

Based on their own practical experience in developing KIS-BO for budget organizations, machine-building enterprises, exploration expeditions, and others, we are deeply convinced that accountants are the best-qualified subject area and only they understand which codes are most convenient for accounting and with which codes can clearly trace the essence of accounting processes. Therefore, the codes of accounting nomenclature for the machine tool IB KIS-BO should be developed primarily by the accountants who will operate this system, and accordingly, the theoretical and practical aspects of building the codes of accounting nomenclature should be reflected in specific methodological recommendations for employees of the accounting services of enterprises and organizations.

\section{Analysis of the latest researches and publications}

It is observed a rapid implemsoftware entation of information technology in all areas of 
the socio-economic environment. The information accounting technology is developing specially quickly. Nowadays, none of the accounting workers can imagine professional activity without a computer. A question of using informational systems and technologies in accounting is the subject of researches for many scholars. Firstly, among the monographs we should highlight the work of Zavgorodniy VP [1], which describes in detail the methodology of designing automated accounting, control, analysis and audit systems. The work of Benko M.M. [2]. Ivakhnenko is very interesting in the application of information systems and technologies in accounting. He made a number of monographs in terms of computer auditing and internal control [3, 4]. Many scholars cover similar issues in articles, investigating trends in the development of information technologies used in accounting [5], peculiarities of the application of computer technologies for automation of accounting in enterprises [6], and others. Special attention is paid to such issues in a number of textbooks and tutorials [7-10], which is explained to a certain extent by the fact that the normative discipline "Information Systems and Technologies in Accounting and Auditing" is being studied by prospective accountants at the Bachelor level of higher educational institutions of Ukraine. However, a number of aspects of building a computer accounting system are generally not disclosed, or are mentioned too superficially in scientific works. Firstly this question is related to the questions of construction of the machine-tool information base KIS-BO and, in particular, the design of the codes of accounting nomenclatures. That is why there is a need od better researches in these questions.

The purpose of the article is to develop a methodology of accounting nomenclature codes of non-automatic informational base KIS-BO by the accounting workers and to show its practical application.

\section{The presentation of the main material}

First of all, we find out the concept of computer accounting system. Some authors [9] interpret it as an automated information system of accounting (AIS-BO). One of the important places in the information systems of enterprises takes up the function of accounting. We note that the study of this function is given sufficient attention in scientific works, for example, in [11]. For full realization of the functions of accounting in enterprise management and reporting, which is provided to external users, it is necessary to collect, register, transmit, accumulate, store and process credentials. For the implementation of this information process, appropriate forms of organization of work, technical means, methods and ways of data conversion, as well as personnel of a certain qualification are required. All of this is an automated information system of accounting, which is an integral part of the enterprise's CIS (AIS).

A computerized or automated information system of accounting is a system in which the information process of accounting is automated through the use of special methods of data processing in which a set of computing, communication and other technical means for the purpose of obtaining and delivering the information required by specialist accountants for the functions of management and financial accounting are used.

KIS-BO implements certain information technologies. For their implementation, KIS-BO has a set of security components, in particular: informational, technical, mathematical, software, linguistic, organizational, technological, legal, methodological and ergonomic support.

Analyzing the purpose of the research, primarily we are interested in the information support KIS-BO, so we emphasize on this concept. The organization of solving any economic task is based on information provision (IZ), which means a set of decisions on the volume, location and forms of organization of information. The decision relates to classification and coding systems, unified documentation systems and data files. The listed components are organized in the form of information base - a set of ordered information used in the operation of IP. The structure of the IZ is shown in Fig. 1.

Information support includes methodical and guidance documents, classification and coding systems and information base.

IB is subdivided into automatic and nonautomatic. IB which includes organizational and information documents is non-automatic. A person can easily understand this kind of IB without computers. Automatic IB it is a set of data recorded on carriers (information arrays).

The non-automatic IB combines all the documents used in the management system, which can be divided into two groups: organizational and informational. 


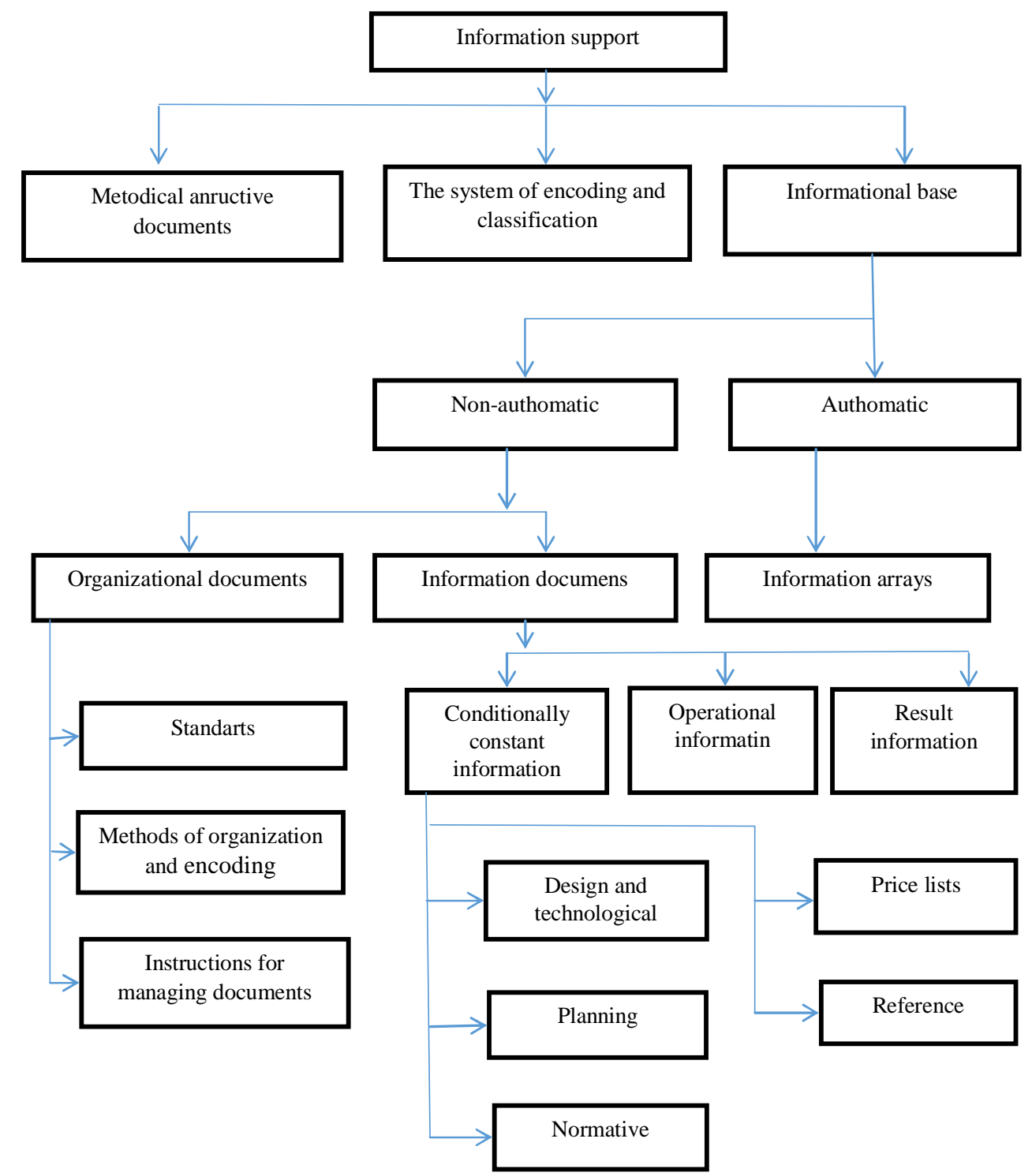

Fig. 1. Structure of information support

The first group includes standards, methods and instructions for the classification and coding of economic information, instructions for filling and adjusting documents. The second group contains documentation with conditional-constant, operational (it records all operations of production and economic activity) and the resulting information.

Conditional information is contained in the design and technological, planning and normative documentation, as well as in price lists.

The rest of the documents circulating in the enterprise management system are operational information (invoices, outfits, acts, accounts, etc.). The rest of the documents circulating in the enterprise management system are operational information (invoices, outfits, acts, accounts, etc.). The results include information, tables, graphs and charts that are obtained after solving the problem.

The machine information base KIS-BU is designed only by specialists in the field of computer systems. Now there are many options for the creation of the CIS. Generalizing approaches to the construction of the computer information systems, which are given in $[7$, p. 254,10, p. 237] we have the following bases: 1) acquisition the of SIS-BO in the form of a set of software called a turnkey solution" (including foreign programs); 2) acquisition of software components and theirintegration; 3) the development of a system, which is given to a third party in order to reduce costs; 4) construction of the information system by own forces. 
CIDs that implement accounting functions and which are represented in the market of software products in Ukraine, what means, that they can be purchased "turnkey", are widely considered in [7,9]. CID accounting is represented by hundreds of PPPs of different companies producing software products and implement the main tasks of the classical sections of accounting - accounting for fixed assets, accounting for labor and wages, etc.

But along with the development of a machine information base, it is equally important for the successful operation of the CIS and, in particular, the KIS-BO, the development of an offmachine IB, in particular its component, as the codes of accounting nomenclature.

Note that classification and encoding are an integral part of the creation and operation of computer ICs. The purpose of classification and encoding is to streamline and reconcile various objects, concepts, properties or other elements of information.

The use of codes can significantly reduce the amount of information and the complexity of its processing at all stages of the technological process of automated data processing.

Based on their own practical experience in developing KIS-BO for budget organizations, machine-building enterprises, and others. we are deeply convinced that the best specialists at the subject area are accountants and only they understand which codes are most convenient for accounting and by which one it is possible to see clearly the essence of accounting processes. On our opinion, the codes of accounting nomenclature for the machine tool IB KIS-BO should be developed by the accountants who will operate this system. To do this, they need to have a deeper theoretical knowledge and practical aspects of performing such a work.

To construct a methodology for carrying out work on the coding of accounting nomenclatures, consider the basic concepts of classification and coding information.

Classification and encoding are two inseparable parts of one process - the translation of various economic information from the natural language into the formalized language of the computer. The basic terms and concepts of this industry are : classification; classification system; classification group; coding; code; code alphabet; digit code; code length; code structure; classifier. The content of these terms and concepts are discussed in detail in [10, p. 63-64].

It should be noted that distinguish two basic methods of classification - hierarchical and facet.

The choice of a particular method of classification depends on the researching purpose of the economic data and should be performed taking into account the satisfaction of the requirements of the entire complex of management tasks.

Why do we encrypt credentials? The purpose of encoding the economic data nomenclature is to provide information in a compact and convenient form. Encoding allows you to set the monotony of the representation of all the signs, bring the information to a form that is convenient for input and processing using computers. The need for coding is due to the peculiarities of economic information: its large volumes, high specific weight of alphabetical information, the predominance of logical operations in the processing, and the growth of volumes of information transmitted through communication channels.

Codes facilitate the recognition of object features and enable their control, simplify and speed up the recording of information on any medium and the provision of various references. The use of codes greatly facilitates the grouping of information, the share of which during data processing is significant. Without the use of the codes for this operation, it would be significantly hampered by the large number of objects taken into account and by their complex, ramified classification.

The use of codes greatly facilitates the grouping of information, the share of which during data processing is significant. Without the use of the codes for this operation, it would be significantly hampered by the large number of objects taken into account and by their complex, ramified classification.

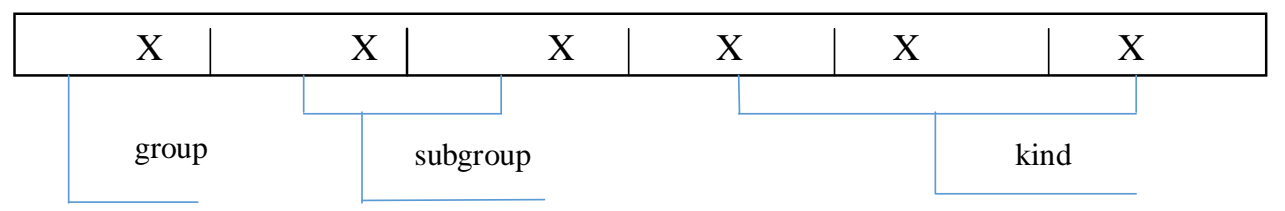

Fig. 2. The example of imagine of the code structure 
Recall that the process of encoding is the assignment of symbols to various objects of a defined nomenclature according to the rules on the basis of the alphabet adopted for this, and the set of rules that assign codes to individual items of the nomenclature, is a method or system of coding.

Numbers, letters, symbols which are used in code marking are called code alphabets. Codes have a certain length $(\mathrm{L})$ - the number of characters in the code and the structure-order of the placement of characters in it. For example, if a set of elements of $\mathrm{A}$ is systematized in 8 groups, within groups of 30 subgroups and in each subgroup of more than 100 species, then the structure of the code can be presented as shown in Fig. 2.The length of the code mark for this set-6 $(\mathrm{L}=6)$.

Codes can be categorized according to the number of characters, in form, depending on the alphabet used for coding, but the most accepted classification is based on the construction principle. On the principle of construction distinguish serial, serial coding systems, the system of repetition, bit (positional) and combined coding system.Let's consider more detailed the essence of the ordinal, serial, bit (positional), combined coding systems and the system of repetition.

The order system is used to encode singlevalued, stable, and simple nomenclatures. It involves assigning objects to digital numbers in the sequence of their placement in the range from a natural number of numbers without spaces. New items of the nomenclature receive the next code mark at the end of the systematic list, and violates the established classification and internal order of coded items. In addition, the classifier, built on the order system, does not distinguish groups of homogeneous features. So: the benefits of the system-the ease of constructing codes, small value, the density of records; disadvantages - it is not expected to group objects by feature; with the advent of new objects in this nomenclature violated accepted classification.

The serial system is intended for the coding of similar simple nomenclatures, having incomplete classification, for example, on two grounds. Encoding an older character, a series of numbers is assigned, in which all elements of the younger sign are encoded in sequence. The size of the series is determined taking into account the number of elements of the younger sign and the necessary to reserve free numbers in the event of expansion of the nomenclature. For new items, the code numbers from the reserve of free numbers of the corresponding series are assigned. Advantages - the most economical of the number of discharges, contains the necessary reserve of free rooms for new objects. Disadvantages - it's difficult to set the optimal number of free numbers and remember, the appearance of a large number of new positions can change the structure of the code.

The repetition system uses the letters or numerals that directly describe the encoded object (e.g., weight, object size, etc.) or data associated with it, such as location, address, etc. Advantages easy to remember, because they express signs, naturally and logically predetermined. Disadvantages-limited use.

Discharge (position) system is used for the coding of complex multi-valued nomenclatures: each classification feature allocates a certain number of digits (positions), which depends on the number of objects in a particular classification group. The discharging system ensures the clarity and logic of the codes, the clear allocation of each classification mark, the convenience for the machine obsolete information, but, at the same time, needs to increase the bit number of the code. In addition, position codes are often characterized by complexity of construction, large length and insufficient flexibility in the case of their structural formation. By the bit coding system, the reserve of free numbers is determined by the very structure of the code. The advantage of bit-code is the clear allocation of each classification mark.

For the coding of large, multi-valued nomenclatures, which are characterized by the subordination and independence of individual classification features, use a combined system based on various combinations of coding principles for all systems under consideration. Combined codes, clear and logical in design, have the most rigorous structure, sufficient flexibility, they can be used for both hierarchical and multi-dimensional nomenclature.

Acquainted with the basic terms and concepts of classification and coding and based on the practical experience of conducting similar works, we will offer a method for constructing codes of accounting nomenclature. To design the codes an accountant is advisable to perform certain work in the following sequence:

1) determine the nomenclature of coded features; 


\section{Shkvir V., Borshchuk I.}

2) make lists (filing cards) of the names of objects of each classification group;

3) systematize each nomenclature taking into account the accepted classification system;

4) choose the most rigorous coding system, that is, determine the rules for writing the code;

5) assign to each element of the nomenclature a code mark (code);

6) finalize the encoded nomenclature in the form of special code books (coders).

First of all, it is necessary to study the features, determine the nomenclature of coded objects, its dynamism, depth of classification.

The coding system is chosen on the basis of constructing various possible options and evaluating their effectiveness. After choosing a coding system, there is a need to collect and prepare the input data necessary for the direct compilation of a systematic summary of the names of classification groups and individual elements of the nomenclature, as well as their code markings.

Simultaneously with the direct compilation, coders develop their management system, intended to update codifiers, their centralized adjustment with the accumulation of information about changes, as well as for the prompt notification of users about the additions and changes made.

The compiled classifiers are experimentally tested, determining their correctness, adaptability to the solution of specific control problems in the conditions of machine data processing; At the same time it is possible to identify certain disadvantages, which are eliminated, making the appropriate adjustments. After approbation and adjustment, the classifiers are approved and put into action.

Apply the proposed coding technique for a specific example. Perhaps there was a need to encode units of measurement of material values. Accountant, based on primary documents to individual, writes a card (preferably heavy paper) the names of all available units of property (full title units, abbreviated, etc.). Let it be the following units of measurement: hryvnia, pennies; kilometer; ton; thing; shares of cents; centimeter; square kilometer; hundredweight; bottle; cubic kilometer; square meter; kilogram; decimetre; square decimeter; cubic meter; gram; roll; square centimeter; milligram; bundle; cubic decimeter; box; cubic centimeter.

In the future it is necessary to systematize units of measurement. After expanding the cards with the written names of units of measurement of material values in groups (by type of units of measurement), we get the following result: cost - hryvnia, penny, shares of cents; length - kilometer, centimeter, decimeter; Square - square kilometer, meter, decimeter, centimeter; volume - liter, cubic kilometer, meter, decimeter, centimeter; mass - ton, centner, kilogram, gram, milligram; natural - a piece, a bottle, a roll, a pack, a box.

It raises the question of choosing the most rigorous coding system for units of measurement, that is, determining the rules for writing their code, so that by applying the coding method to each element of the nomenclature (units of measurement in this case) eventually assign a code mark (code) and finally issue coded nomenclature in the form of special code books (codifiers).

Knowing the advantages and disadvantages of different coding systems, given above, we encode units of measurement for order, serial and bit systems. The results will be presented in tabular form.

In order to select the final version of the coding, we analyze the results obtained according to different criteria of the effectiveness of constructing the code of units of measurement of material values, in particular: the small length of the code (the probability of occurrence of errors decreases when the code is entered into the computer); record density; possibility of grouping on a certain sign; the possibility of assigning codes to new nomenclatures without breaking the code structure, etc.

By the ordinal coding system, we assigned the ordinal numbers of each unit of measurement (see Table 1), based on the rules for constructing such codes. The last ordinal code of the unit of measurement is 25 . The length of the code in this case is two digits. The advantages of this encoding system are the ease of constructing codes, the small size, the density of records. Disadvantages - the grouping of objects is not foreseen; with the appearance of new objects of this nomenclature breaks the accepted classification, that is, if a new unit of measurement, for example a mile, appears, then it assigns the next free serial number -26 . Since the mile will no longer be in the group of units of length, it is difficult to group by, for example the type of unit of measurement "length", etc. 
Codes of measurement units for different coding systems

\begin{tabular}{|l|c|c|c|}
\hline \multirow{2}{*}{$\begin{array}{l}\text { Name of the type and unit of measurement of } \\
\text { material value }\end{array}$} & \multicolumn{3}{|c|}{ Unit of measurement code } \\
\cline { 2 - 4 } Quantitative & ordinal & serial & bit \\
\hline Ghruvni & & $01-06$ & 10 \\
\hline kopeck & 02 & 01 & 11 \\
\hline shares of kopeck & 03 & 03 reserve $04-06$ & 12 \\
\hline Lenght & & $07-12$ & 20 \\
\hline kilometr & 04 & 07 & 21 \\
\hline centimetr & 05 & 08 & 22 \\
\hline decimetr & 06 & 09 reserve10-12 & 23 \\
\hline Square & & $13-20$ & 30 \\
\hline square kilometr & 07 & 13 & 31 \\
\hline square meter & 08 & 14 & 32 \\
\hline square decemetr & 09 & 15 & 33 \\
\hline square centimetr & 10 & 1617 reserve-20 & 34 \\
\hline Volume & & $21-29$ & 40 \\
\hline liter & 11 & 21 & 41 \\
\hline cubic kilometr & 12 & 22 & 42 \\
\hline cubic meter & 13 & 23 & 43 \\
\hline cubic decemetr & 14 & 24 & 44 \\
\hline cubic centimetr & 15 & 25 reserve $26-29$ & 45 \\
\hline Weight & & $30-39$ & 50 \\
\hline ton & 16 & 30 & 51 \\
\hline centner & 17 & 31 & 52 \\
\hline kilograms & 18 & 32 & 53 \\
\hline grams & 19 & 33 & 54 \\
\hline milligram & 20 & 34 reserve $35-39$ & 55 \\
\hline Natural & & $40-49$ & 60 \\
\hline piece & 21 & 40 & 61 \\
\hline bottle & 22 & 41 & 62 \\
\hline roll & 23 & 42 & 63 \\
\hline packet & 25 & 44 reserve45-49 & 64 \\
\hline box & & & 65 \\
\hline
\end{tabular}

Let's code units of measurement by serial coding system. For our example, for each type of measurement unit, let's take a series of numbers, taking into account the existing number of units of measurement within each species, and we will necessarily leave the reserve of free numbers for new units of measurement of this type (in case of such appearance). The reserve is difficult to determine, it is established, based on practical experience, real economic and trade relations of the enterprise, etc. The advantage: it is the most economical system by the number of discharges, contains the necessary reserve of free numbers for new objects.

Disadvantages - it is difficult to establish and remember the optimal amount of free numbers. The appearance of a large amount of new positions can change the structure of the code. So, we do not know how many new units of measurement may appear. Units, which are left for this kind of unit of measurement of free numbers, are sometimes not enough. For example, among the cost units of measurement will appear such cost units of measurement, as the euro, the dollar, yuan, yen. The unit value, the yen, will no longer have the free reserved code in the "cost" group, since the remaining codes are assigned to the euro, the dollar and the yuan. It will break the classification. If you leave a large reserve of free numbers for each type of measurement unit (for example, 10000), then the value of the code will increase (the code length for our example will be 5 symbols), which will increase the likelihood of an error occurring during the set of information.

By the bit coding system, the reserve of free numbers is determined by the structure of the code. Since we have six types of measurement units, and within each of the types there are no more than five actual units of measurement, so for our example, the structure of the code of the units of measurement will be as follows: 


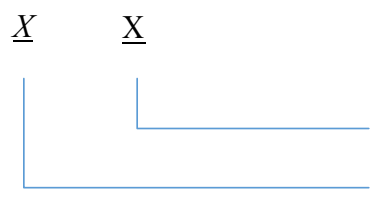

The unit of measurement inside the species

For types of measurement units, one digit is assigned and one digit for the actual measurement units. Therefore, we can encode nine types of measurement units (volume, weight, natural, etc.) and nine other actual units of measurement inside each species. You can leave two digits for the units of measurement (99 positions), and the code will be three-digit. If necessary (there are more than ten types of measurement units) the length of the code will have four digits. It all depends on a deep and comprehensive analysis of the work of a particular company, analysis of partner relationships, etc. For our example, the construction of the code of measurement units by the bit coding system is optimal from the positions of machine processing information (grouping information, sampling, etc.).

The advantage of bit-code is the clear allocation of each classification feature. After making a final decision regarding the encoding of units of measurement of material values, the cards display the designed code symbols (codes) and ultimately, based on such cards, codebooks (coders) are compiled mostly in electronic form. Again, we note that accountants who will use KIS-BO will build such codes the best, since they only have deep knowledge of accounting nomenklatura. Of course, they may need help from specialists of KIS-BO developers or firms that bind existing market-based accounting software products to specific terms of use. But such assistance will only concern information about length, type, format, etc. characteristics of the requisites programmed in the system in the structure of the array records of the machine information base. This will allow the accountant to determine the maximum possible length of the relevant codes of accounting nomenclature, which he will develop for the onmachine information center KIS-BO acquired by the enterprise in the market of software products for further exploitation.

\section{Conclusions and perspectives of further research}

Consequently, the codes of accounting nomenclature, as one of the components of the machine-tool information base KIS-BO, should primarily develop accountants who will operate this system. Using the coding method proposed in the article and having a thorough knowledge of the accounting processes of an enterprise, only the accountant can design effective codes of accounting nomenclatures. That will allow to establish the uniformity of representation of all signs, to bring information into a form convenient for input and processing by means of computers, will be the most rational the point of view of their construction, etc.

The subject of further research is the creation of a methodology for designing primary accounting documents that would correspond to the form of construction of the requirements for automated processing of information as an important component of the off-vehicle information base KIS-BO.

\section{References}

1. Zavgorodniy, V. P. (1998). Avtomatyzatsiia bukhhalterskoho obliku, kontroliu, analyzu ta audytu. [Automation of accounting, control, analysis and audit]. Kyiv: ASK (Economics, Finance, Law).

2. Benko, M. M. (2010). Informatsiini systemy i tekhnolohii v bukhhalterskomu obliku [Information systems and technologies in accounting]. Kyiv: Kyiv. nats auction. - econ. Unt.

3. Ivakhnenkov, S. V. (2010). Informatsiini tekhnolohii audytu ta vnutrishnohospodarskoho kontroliu $v$ konteksti svitovoi informatsii [Information technology of audit and internal control in the context of world information. Zhytomyr: PE "Ruta"]

4. Ivakhnenkov, S. V. (2005). Kompiuternyi audyt: kontrolni metodyky i tekhnolohii [Computer audit: control techniques and technologies]. K: Knowledge

5. Pikulina, N. Yu. \& Shilo, L. A. (2013). Trends in the development of information technologies used in accounting, auditing and internal control. Problemy ekonomiky transport. [Problems of Transport Economics],6, 68-75. [in Ukrainian].

6. Polishchuk, O. M. (2014). Peculiarities of application of computer technologies for automation of accounting on enterprises. Ekonomichni nauky. Seriia "Oblik i finansy". [Economic sciences. The series "Accounting and Finance"], 11 (41), part 2, 287-292. [in Ukrainian].

7. Ivakhnenkov, S. V. (2013). Informatsiini tekhnolohii v orhanizatsii bukhhalterskoho obliku ta audytu [Information technology in the organization of accounting and auditin]. Kyiv: Znannia-Pres [in Ukrainian].

8. Susidenko, V. T. (2016). Informatsiini systemy i tekhnolohii [Information systems and technologies]. Kyiv: Tsentr uchbovoi literatury. [in Ukrainian].

9. Shuremov, E. L., Umnov, E. A., \& Voropaev, T. V. (2001). Avtomatizirovannye infolrmacionnye sistemy buhgalterskogo ucheta, analiza, audita. [Automated informational accounting systems, analysis, audit]. SPb: Perspektyva. [in Russian].

10. Shvvir, V. D., Zagorodniy, A. G. \& Vysochan, O. S. (2017). Informatsiini systemy $i$ tekhnolohii $v$ obliku ta audyti [Information systems and technologies in accounting and auditing: textbook].(4thed.,rev). Lviv: Lviv Polytechnic Publishing House. [in Ukrainian].

11. Lemishovska, O. (2015). Metodical bases of fundamental works on accounting by comparative aspect. Economics, Entrepreneurship, Management, 2 (2), 27-32. https://doi.org/10.23939/eem2015.02.02. 